\title{
Les nouvelles données sur les origines de l'église de Saint-Hymetière (Jura)
}

\section{David Billoin}

\section{Q OpenEdition}

10 Journals

\section{Édition électronique}

URL : https://journals.openedition.org/cem/11917

DOI : 10.4000/cem. 11917

ISSN : 1954-3093

\section{Éditeur}

Centre d'études médiévales Saint-Germain d'Auxerre

\section{Édition imprimée}

Pagination : 81-85

ISSN : 1623-5770

\section{Référence électronique}

David Billoin, «Les nouvelles données sur les origines de l'église de Saint-Hymetière (Jura) », Bulletin du centre d'études médiévales d'Auxerre | BUCEMA [En ligne], 15 | 2011, mis en ligne le 22 août 2011, consulté le 22 septembre 2022. URL : http://journals.openedition.org/cem/11917 ; DOI : https:// doi.org/10.4000/cem. 11917

Ce document a été généré automatiquement le 22 septembre 2022.

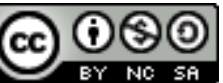

Creative Commons - Attribution - Pas d'Utilisation Commerciale - Partage dans les Mêmes Conditions 4.0 International - CC BY-NC-SA 4.0

https://creativecommons.org/licenses/by-nc-sa/4.0/ 


\title{
Les nouvelles données sur les origines de l'église de Saint- Hymetière (Jura)
}

\author{
David Billoin
}

1 Joyau des débuts de l'architecture romane jurassienne, l'église de Saint-Hymetière se dresse à l'écart du village actuel, dans l'ample vallon de la Valouse (fig. 1). Entouré d'un cimetière clos d'un mur, l'édifice comprend une nef à trois vaisseaux, un transept débordant et un chevet primitif à trois absides semi-circulaires. À la croisée du transept, un clocher octogonal s'élève depuis une souche carrée, offrant à cet édifice une silhouette particulière. Des baies romanes et un décor originel de lésènes ornent l'édifice; ce décor d'arcature est caractéristique des débuts de l'architecture romane, daté avant $1050^{1}$.

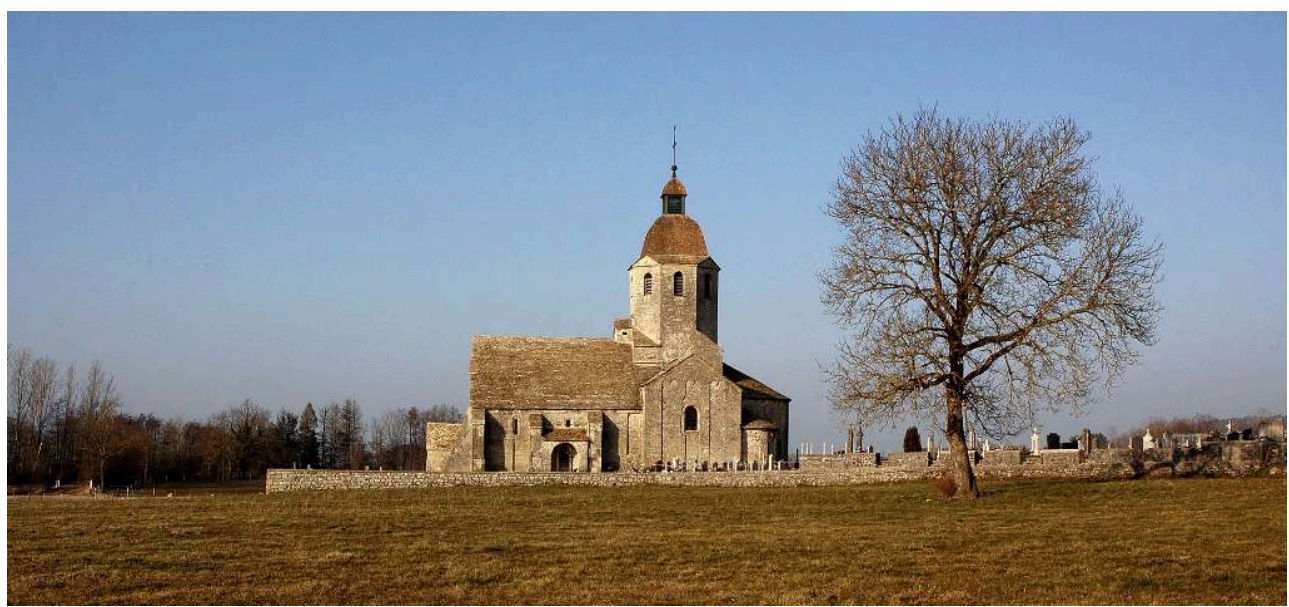

Fig. 1 - Saint-Hymetière, l'église à l'écart du village (cl. R. Lepennec).

3 Peu de renseignements éclairent l'origine du site, hormis la mention d'un certain Hymeterius à une époque indéterminée dans un martyrologe de l'abbaye de SaintClaude, aujourd'hui disparu. Une tradition rapporte qu'Hymeterius, moine de ce 
monastère, quitta son abbaye au cours des $\mathrm{V}^{\mathrm{e}}-\mathrm{VI}$ siècles pour se retirer dans cette vallée, alors "déserte ", où il fonda un ermitage. Peu à peu, des habitats se formèrent autour de sa cellule et donnèrent naissance au village qui porte son nom. À sa mort, ses vertus le firent honorer comme saint et il aurait été inhumé dans une chapelle placée sous son vocable. Un prieuré aurait été ajouté à ces constructions au sud de l'église, mais il aurait été détruit en même temps que le village lors du passage des troupes de Louis $\mathrm{XI}, \mathrm{au} \mathrm{XV}^{\mathrm{e}}$ siècle. Reconstruit plus loin, le village s'est peu à peu éloigné de l'église et s'est fixé à son emplacement actuel.

4 La première mention textuelle d'un établissement monastique est donnée par un diplôme du 4 décembre 861, sous le terme de cellula. Charles le Chauve le restitue en effet à la cathédrale Saint-Vincent de Mâcon, à laquelle la paroisse reste liée jusqu'à la Révolution. Une visite pastorale signale le tombeau de Saint-Hymetière en 1613, élevé en pierre et jamais ouvert ${ }^{2}$. Il se dressait derrière le maître-autel de l'église et fut ouvert le 22 octobre 1653, puis ses reliques seront installées dans une châsse exposée dans le chœur de l'église. Elle contient les ossements d'un individu adulte masculin assez complet et quelques os d'une autre personne. L'étude et les datations sont en cours.

5 Les travaux de réfection engagés par les Monuments historiques sur l'église ont été précédés de sondages archéologiques demandés par le SRA de Franche-Comté en $2010^{3}$. En effet, un projet de pose de drains dans le sous-sol autour de l'édifice était susceptible d'affecter des vestiges, en particulier des sépultures entraperçues lors d'une opération similaire réalisée en 1986. Quatre sondages, totalisant $28 \mathrm{~m}^{2}$, ont été ouverts au droit des maçonneries extérieures de l'édifice en fonction des espaces disponibles lors des travaux (fig. 2). Ils ont atteint le sous-sol géologique, entre $1,60 \mathrm{~m}$ et $2 \mathrm{~m}$ de profondeur selon le pendage du terrain naturel. Près d'une trentaine de sépultures ont été découvertes et étudiées, s'échelonnant des $\mathrm{VI}^{\mathrm{e}}-\mathrm{VII}^{\mathrm{e}}$ siècles à la fin de la période médiévale. 


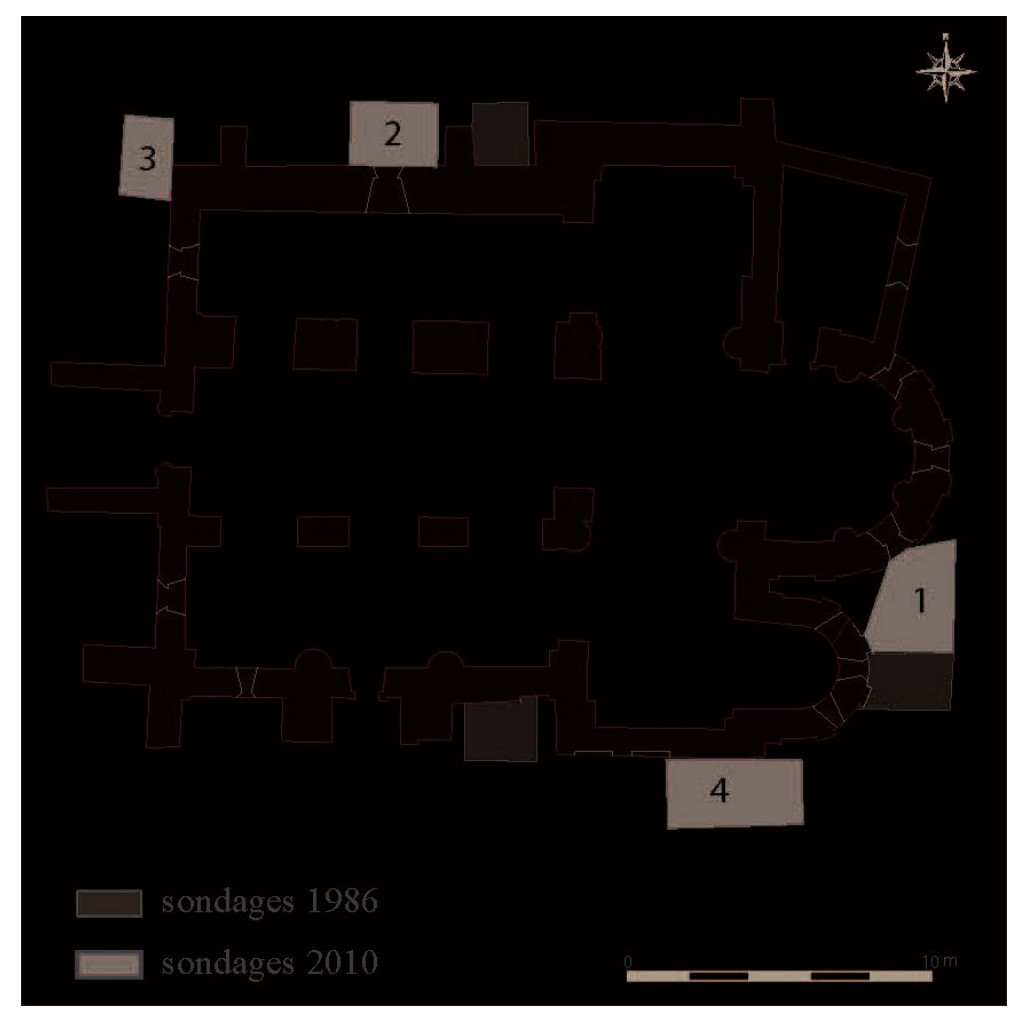

Fig. 2 - Saint-Hymetière, localisation des sondages archéologiques (D. Billoin, Inrap).

6 Hormis un «bruit de fond» de l'Antiquité, l'occupation du site débute par des inhumations en coffre de dalles verticales, caractéristiques du domaine romanoburgonde, reconnues dans au moins deux sondages (fig. 3). L'architecture imposante de ces tombes ainsi qu'un phénomène d'attraction, observé à proximité immédiate du chœur de l'église, posent la question d'un édifice religieux dès cette époque, en relation avec l'hypothétique tombe de saint Hymetière. Une datation radiocarbone réalisée sur les os d'un individu de l'une de ces sépultures confirme un enfouissement entre 544 et 646 apr. J.-C. (Ly-15336).

Plusieurs portions de maçonneries antérieures à l'église romane sont attestées, mais délicates à interpréter dans l'ensemble car les fenêtres de sondages sont trop réduites. Une maçonnerie, constituée de blocs bruts de moraine et de moellons ébauchés liés à un mortier de chaux jaune à fin gravier et de sable en fondation étroite, est conservée sur 5 à 6 assises de hauteur $(0,80 \mathrm{~m})$. Quelques pierres sont disposées de chant ou ponctuellement de façon verticale. L'extrémité, un vraisemblable retour, se signale par de gros blocs de moraine empilés. Le sommet de cette maçonnerie est écrêté et repris parfaitement par l'angle formé par le mur gouttereau nord et le bras du transept de l'église romane. En chronologie relative, cette maçonnerie recoupe un niveau de sol en terre battue, comportant des aménagements (trou de poteau, dallage) et une occupation livrant de la faune et de la céramique scellant l'horizon funéraire sousjacent. Une partie de ce mur prend directement appui sur l'un des couvercles monolithiques de ces tombes mérovingiennes (fig. 3). Une datation radiocarbone effectuée sur du charbon de bois provenant de cette occupation indique un âge calibré à 690-885 apr. J.-C., avec un pic de probabilité significatif en 776 (Ly-15334), plaçant ce vestige maçonné à une date postérieure. La superposition parfaite de l'église romane 
avec cette maçonnerie évoque fortement la présence d'un édifice religieux antérieur, peut-être la cellula restituée le 4 décembre 861 par Charles le Chauve.

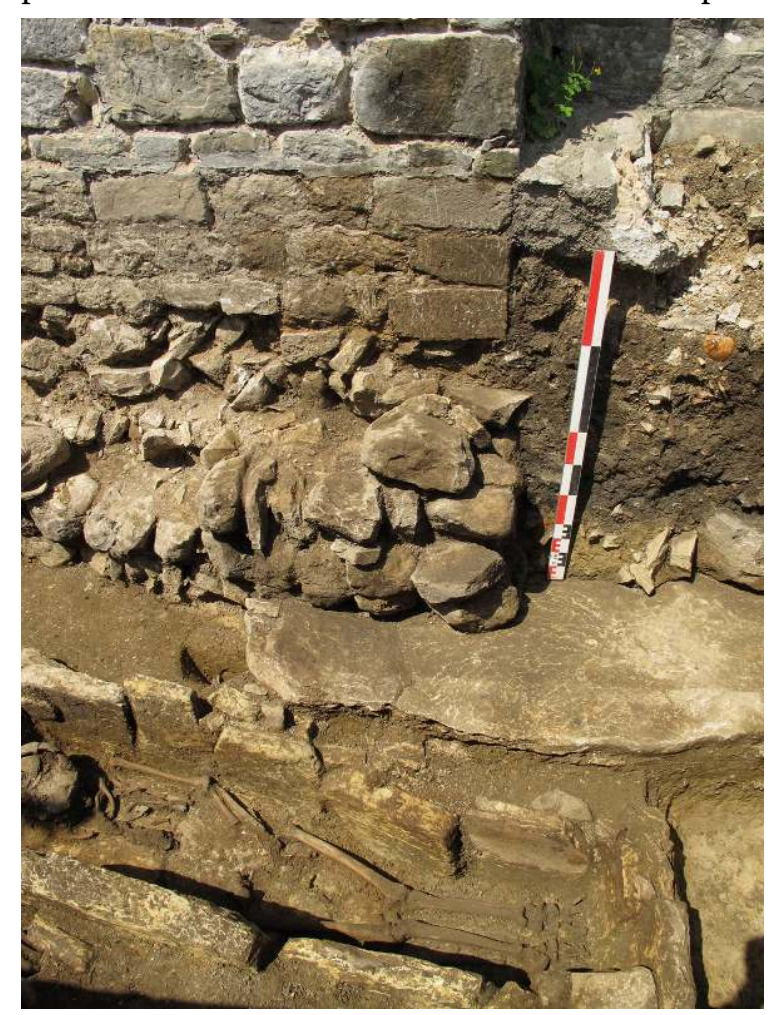

Fig. 3 - Saint-Hymetière, vue d'ensemble du sondage $n^{\circ} 4$, avec les vestiges d'un édifice antérieur à l'église romane s'appuyant sur le couvercle d'une tombe mérovingienne (cl. D. Billoin, Inrap).

8 Un horizon funéraire révèle en particulier des sépultures en coffres naviformes, épousant la forme du corps, construits en moellons grossièrement équarris montés en lit de pose horizontaux. Ces architectures funéraires sont rencontrées régionalement $\mathrm{du} \mathrm{VII}{ }^{\mathrm{e}} \mathrm{au} \mathrm{XI}$ siècle et sont systématiquement associées à un lieu de culte. L'une d'elle a été datée par radiocarbone de 898 à 1021 apr. J.-C. (Ly-15335), alors que d'autres sépultures sont recoupées par les fondations de l'église romane.

Enfin, outre des inhumations en cercueil datées de l'époque médiévale à plus récente présence de chapelets et de médailles religieuses -, trois inhumations en coffre, situées au chevet de l'église, sont datées des $\mathrm{XII}^{\mathrm{e}}$-XIII ${ }^{\mathrm{e}}$ siècles par leur dépôt funéraire, constitué d'un calice, d'une patène et d'un petit pot globulaire. Ces attributs sacerdotaux permettent d'identifier des tombes de prêtres en un lieu de prédilection pour leur enterrement. D'eux d'entre eux sont atteints d'hyperostose, maladie fréquente en milieu monastique - exemple de Gigny dans ce volume.

10 L'ensemble des informations recueillies à l'occasion de ces sondages renouvelle singulièrement la question des origines de cette église, dans le sens de la tradition légendaire autour de saint Hymeterius. 


\section{NOTES}

1. C.S APIN, "Saint-Hymetière", in Éclats d'histoire. Dix ans d'archéologie en Franche-Comté, Besançon, 1995, p. 370-371 et C. SAPIN, Bourgogne romane, Dijon, 2006, p. 51-52.

2. P. LACROIX, Églises jurassiennes romanes et gothiques, Besançon, 1981.

3. C. FOSSURIER, H. GUIRAUD, S. HUMBERT et V. LAMY, Aux origines de l'église de Saint-Hymetière (VI ${ }^{e}-\mathrm{VII}{ }^{e}$ ) XXe siècles), Jura, rapport Inrap, 2010.

\section{INDEX}

Mots-clés : église

Index géographique : France/Saint-Hymetière 